\title{
Lipid Peroxidation of Liposome Induced by Glucosone
}

\author{
Tsutomu Nakayama,* Munetaka Yamada, Toshihiko Osawa, \\ and Shunro KAWAKISHI \\ Department of Food Science and Technology, Faculty of Agriculture, \\ Nagoya University, Nagoya 464-01, Japan \\ (Received January 29, 1992)
}

\begin{abstract}
Summary Lipid peroxidation of liposome made of egg lecithin was induced by glucosone (D-arabino-hexos-2-ulose), a secondary product of Maillard reaction or glycation of protein. Lipid peroxidation was assessed with measurement of TBARS (thiobarbituric acid reacting substances), POV (peroxide value), and HPLC measurement of MDA (malondialdehyde). EDTA and DTPA (diethylenetriamine-pentaacetic acid) inhibited the lipid peroxidation assessed by each method described above, indicating involvement of metal ions. The observed reduction of $\mathrm{Fe}^{3+}$ to $\mathrm{Fe}^{2+}$ by glucosone might be a critical step of the lipid peroxidation. Our findings suggest a possible role of lipid peroxidation of low-density lipoproteins (LDL) induced by glucosone in atherosis caused by diabetes mellitus.
\end{abstract}

Key Words lipid peroxidation, glucosone, glycation, Maillard reaction, Amadori compound, TBARS, MDA

LDL atherogenicity is a representative diabetic complication. Recently oxidative damage of LDL has been suggested as an origin of atherosclerosis (1). In this regard, Hunt et al. suggest that autoxidative glycosylation (glycation) of LDL and the following lipid peroxidation of its lipid moiety may affect cellular interactions of LDL and result in atherosclerosis (2). They observed an increase of TBARS (thiobarbituric acid reacting substances) and POV (peroxide value) in LDL incubated with glucose in the presence of $\mathrm{Cu}^{2+}$. They concluded that the lipid peroxidation was due to the reduction of metal ion and consequent active oxygen formation. Sakurai et al. reported that glycated polylysine or glycated LDL induced lipid peroxidation in the presence of $\mathrm{Fe}^{3+}$-ADP $(3,4)$. They suggest that

Abbreviations: TBA, thiobarbituric acid; TBARS, thiobarbituric acid reacting substances; POV, peroxide value; MDA, malondialdehyde; DTPA, diethylenetriaminepentaacetic acid; $N^{\alpha}$ - $t$-BOC- $N^{\varepsilon}$-fructoselysine, $N^{\alpha}$ - $t$-butoxycarbonyl- $N^{\varepsilon}$-(1-deoxy-D-fructos-1-yl)-L-lysine; fructoselysine, $N^{\varepsilon}$-(1-deoxy-D-fructos-1-yl)-L-lysine; MLV, multi lamellar vesicles; SUV, small unilamellar vesicles; glucosone, D-arabino-hexos-2-ulose.

* To whom correspondence should be addressed. 
Amadori compound, the initial product of glycation, chelated $\mathrm{Fe}^{3+}$, resulting in an oxidant formation responsible for the lipid peroxidation. However, neither of these two research groups has attributed the lipid peroxidation to any degradation products of Amadori compounds. Recently Kawakishi et al. reported that glucosone (D-arabino-hexos-2-ulose) was formed by the oxidative degradation of Amadori compounds in the presence of $\mathrm{Cu}^{2+}(5)$. Therefore, it is reasonable to expect that glucosone was produced by the degradation of Amadori compounds formed in the reaction of LDL or polylysine with glucose.

Glucosone is also formed as one of the main products in oxidative browning degradation of $\mathrm{N}$-D-glucoside (6) or in $\gamma$-radiolysis of D-glucose and D-fructose both under aerobic and anaerobic conditions (7-10), and has been implicated as a mutagenic agent (11). Concerning its biological action on mammalian cells, $2 \mathrm{~mm}$ of glucosone is a strong inhibitor of growth, protein- and DNA-synthesis of in vitro cultured Ehrlich ascites tumor cells (12). In spite of these studies, the mechanism of its biological effects remains unknown.

Since ascorbic acid causes lipid peroxidation of liposome in the presence of metal ions (13-15), glucosone, we expected, would also induce lipid peroxidation of liposome owing to the same enediol structure as that of ascorbic acid. Thus, we tried to detect lipid peroxidation induced by glucosone in a model system in order to clarify the role of glycation in LDL atherogenicity and the mechanism of other biological effects of glucosone.

\section{MATERIALS AND METHODS}

Reagents. Lecithin made from egg for biochemical purposes and urea were obtained from Wako Pure Chemical Industries, Ltd. (Osaka, Japan). TBA (2thiobarbituric acid) was purchased from E. Merck Japan Ltd. (Tokyo, Japan). 2Hydroxypyrimidine, dicetylphosphate and catalase from bovine liver were obtained from Sigma Chemical Co. (St. Louis, MO, U.S.A.). Superoxide dismutase (SOD) was purchased from ICN Immuno Biological (Lisle, IL, U.S.A.). Glucosone (D-arabino-hexos-2-ulose) was prepared from glucose phenylosazone according to the method of Bayne (16). $\quad N^{\alpha}$ - $t$-BOC- $N^{\varepsilon}$-fructoselysine $\left(N^{\alpha}\right.$-t -butoxycarbonyl$N^{\varepsilon}$-(1-deoxy-D-fructos-1-yl)-L-lysine) was prepared according to the method of Njoroge et al. (17). Fructoselysine ( $N^{\varepsilon}$-(1-deoxy-D-fructos-1-yl)-L-lysine) was obtained by the hydrolysis of $N^{\alpha}-t$-BOC- $N^{\varepsilon}$-fructoselysine with $70 \%$ trifluoro acetic acid. All other chemicals were reagent grade and were used without further purification.

Preparation of liposome. Lecithin $(100 \mathrm{mg}$ ) and $5 \mathrm{mg}$ of dicetylphosphate were dissolved in $10 \mathrm{ml}$ of chloroform. The solution in a round-bottomed flask was evaporated with a rotary evaporator and then with a vacuum pump in order to make a dried thin film of phospholipid on the inner surface of the flask. Ten milliliters of $10 \mathrm{~mm}$ sodium phosphate buffer ( $\mathrm{pH} \mathrm{7.4)}$ was poured into the flask and sonicated in an ultrasonic cleaner (Bransonic 220, Branson, U.S.A.). The resulting 
MLV (multi lamellar vesicles) solution was transferred into a $20 \mathrm{ml}$ Teflon bottle and bubbled with $\mathrm{N}_{2}$ gas for $30 \mathrm{~s}$. The sealed bottle was placed in water in the cavity of a cup-horn-type sonicator (Insonator 201M, Kubota, Japan) and sonicated at $100 \mathrm{~W}$ for $10 \mathrm{~min}$. We confirmed the phase change of the liposome from MLV to SUV (small unilamellar vesicles) by filtration of the solution through a cellulose nitrate filter (0.2 $\mu \mathrm{m}$ : Dismic-25, Toyo Roshi Kaisha, Ltd., Japan).

Incubation of liposome. SUV solution ( $10 \mathrm{mg}$ liposome $/ \mathrm{ml})$, mixed with other reagents, was diluted with $10 \mathrm{~mm}$ sodium phosphate buffer ( $\mathrm{pH} 7.4$ ) to produce the final concentration of liposome $(1 \mathrm{mg} / \mathrm{ml})$. This reaction mixture was incubated at $40^{\circ} \mathrm{C}$ for the indicated times under aerobic conditions.

Measurement of TBARS. One milliliter of the reaction mixture, $0.1 \mathrm{ml}$ of $10 \%$ methanolic solution of $10 \%$ BHT, and $2 \mathrm{ml}$ of TBA solution (15\% w/v TCA, $0.375 \% \mathrm{w} / \mathrm{v}$ TBA and $0.25 \mathrm{~N} \mathrm{HCl}$ ) were mixed, heated for $15 \mathrm{~min}$ in a boiling water bath, and treated according to the method of Buege and Aust (18). The results were calculated as the equivalent of MDA.

Measurement of POV. One milliliter of the reaction mixture was mixed with $5 \mathrm{ml}$ of chloroform : methanol $(2: 1)$ and treated according to the method of Buege and Aust (18). Standardization of the reaction was done by using cumene hydroperoxide as the peroxide standard.

Determination of malondialdehyde (MDA) with high-pressure liquid chromatography (HPLC). The amount of MDA formed during both peroxidation of liposome and acid-hydrolysis of the peroxidation products was measured with HPLC according to the method of Osawa and Shibamoto (19). Briefly, $1 \mathrm{ml}$ of reaction mixture, $0.1 \mathrm{ml}$ of $1.2 \mathrm{~N} \mathrm{HCl}$ solution, $0.1 \mathrm{ml}$ of $0.12 \mathrm{M}$ urea solution, and $10 \mu 1$ of $10 \%$ BHT solution were mixed and heated in boiling water for $60 \mathrm{~min}$. Under these conditions, MDA quantitatively reacts with urea to give 2-hydroxypyrimidine. After cooling, the mixture was passed through SEP-PAK (C18: Waters, Milford, MA, U.S.A.) with $10 \mathrm{mM}$ phosphate buffer and was then adjusted to $5 \mathrm{ml}$ of the final volume. Fifty microliters of sample was injected into a Develosil ODS-5 reverse-partition column (4.6 i.d. $\times 250 \mathrm{~mm}$; Nomura Chemical Co., Ltd., Aichi, Japan). Distilled water was used as the solvent. Detection was carried out with an UV detector at $309 \mathrm{~nm}$. The amount of MDA was calculated by standardization with the peak height of authentic 2-hydroxypyrimidine.

Determination of $\mathrm{Fe}^{2+}$ concentration. Reduction of $\mathrm{Fe}^{3+}$ by glucosone or fructoselysine was monitored by determination of $\mathrm{Fe}^{2+}$ according to the method of Tien et al. (20). Sodium phosphate buffer $(5 \mathrm{mM}, \mathrm{pH} 7.4)$ containing $0.2 \mathrm{~mm}$ of $\mathrm{FeCl}_{3}, 5 \mathrm{mM}$ of ortho-phenanthroline plus $10 \mathrm{mM}$ of glucosone or fructoselysine was kept at room temperature. At the indicated times the absorbance due to the ferrous phenanthroline chelate was measured at $510 \mathrm{~nm}$. The amount of $\mathrm{Fe}^{2+}$ was calculated by standardization with a control sample of $\mathrm{Fe}^{2+}$. 


\section{RESULTS}

First we compared the activity of three compounds, which possibly form enediol structure, on lipid peroxidation of the liposome. We incubated the liposome with glucosone, ascorbic acid, and fructoselysine (which is an Amadori compound formed in the initial glycation step) (Fig. 1). No increase of absorbance at $535 \mathrm{~nm}$ after reaction of glucosone with TBA shows that glucosone and/or its degradation products did not contribute to the TBA value (Fig. 1(a)). This was also confirmed with the results of the HPLC method described later. Therefore, the increase of TBA value observed in the reaction mixture of the liposome and glucosone is due to lipid peroxidation, although its rate was slower than in the case of ascorbic acid (Fig. 1(a)). On the other hand, fructoselysine showed no enhancing effect in comparison with the control sample, which slowly autoxidized (Fig. 1(b)). Next, we examined the role of metal ions. When the liposome was incubated with glucosone in the presence of $1 \mu \mathrm{M}$ EDTA or $1 \mu \mathrm{M}$ DTPA, the rate of lipid peroxidation was almost the same as that of control (Fig. 2). Addition of $\mathrm{Cu}^{2+}$ or $\mathrm{Fe}^{3+}$ to the reaction mixture containing glucosone enhanced the lipid peroxidation dose-dependently (Fig. 3). Under the same conditions, addition of these metal ions themselves had no effect on the lipid peroxidation of the liposome in the absence of glucosone (Fig. 3). As to the concentrations of the metal ions in these experiments, $\mathrm{Cu}^{2+}$ was more effective on the lipid peroxidation than $\mathrm{Fe}^{3+}$. These results indicate that trace metal ions in the reaction mixture were responsible for the lipid peroxidation induced by glucosone. Since reduction of $\mathrm{Fe}^{3+}$ to $\mathrm{Fe}^{2+}$ is a critical

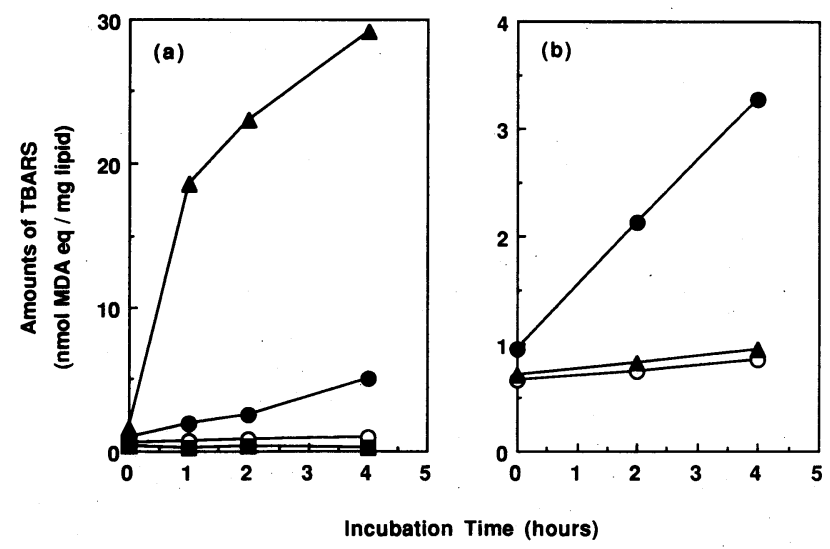

Fig. 1. Increase of TBARS in liposomes induced by ascorbic acid, glucosone, and fructoselysine. SUV solution ( $1 \mathrm{mg}$ liposome/ml) was incubated with $1 \mathrm{mM}$ ascorbic acid, glucosone or fructoselysine at $40^{\circ} \mathrm{C}$. (a) $\bigcirc$, control; $\square$, control glucosone (in the absence of liposome); $\bullet$, glucosone; $\boldsymbol{\Delta}$, ascorbic acid. (b) $\bigcirc$, control; $\bullet$, glucosone; $\boldsymbol{\Delta}$, fructoselysine. 


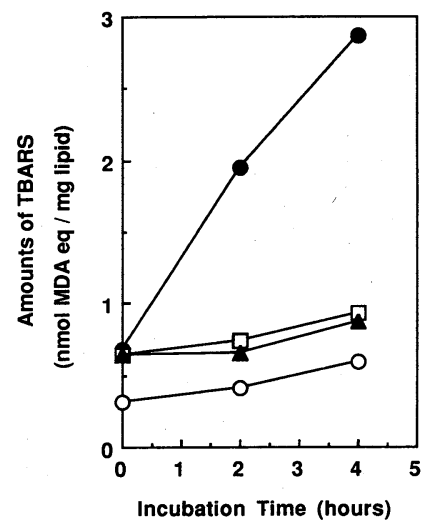

Fig. 2. Effects of EDTA and DTPA on the increase of TBARS in liposomes induced by glucosone. SUV solution (1 mg liposome $/ \mathrm{ml}$ ) was incubated with 1 $\mathrm{mM}$ glucosone at $40^{\circ} \mathrm{C}$ with or without metal ion chelators. $\bigcirc$, control; $\bigcirc$, glucosone; $\square$, glucosone with $1 \mu \mathrm{M}$ of EDTA; $\boldsymbol{\Delta}$, glucosone with $1 \mu \mathrm{M}$ of DTPA.
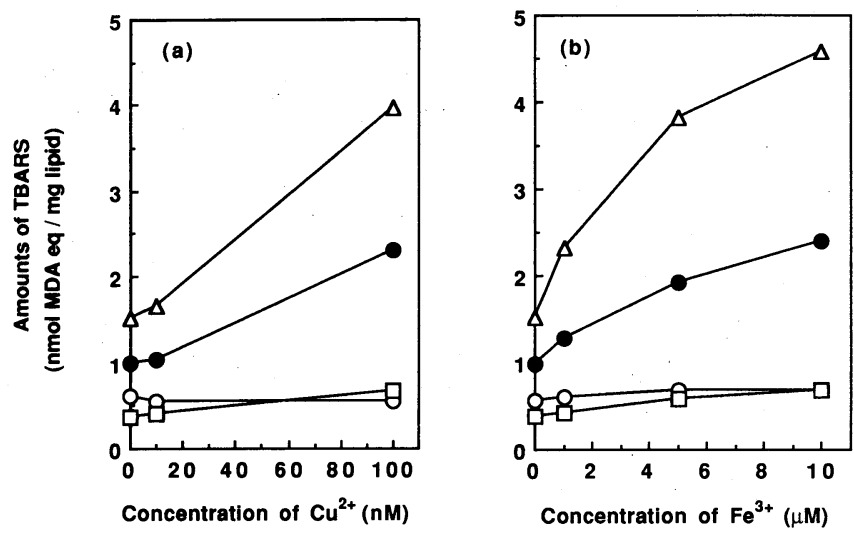

Fig. 3. Concentration dependency of metal ions on the increase of TBARS induced by glucosone. SUV solution ( $1 \mathrm{mg}$ liposome/ml) was incubated with $\mathrm{Cu}^{2+}$ (a) or $\mathrm{Fe}^{3+}$ (b) for the indicated times. $\bigcirc, 0 \mathrm{~h} ; \bullet, 2 \mathrm{~h} ; \triangle, 4 \mathrm{~h} ; \square, 4 \mathrm{~h}$ in the absence of glucosone.

step of lipid peroxidation caused by ascorbic acid (15), we compared $\mathrm{Fe}^{3+}$. reduction rate by glucosone and that by fructoselysine. Figure 4 shows that both compounds reduced $\mathrm{Fe}^{3+}$ to $\mathrm{Fe}^{2+}$, but the reduction rate by glucosone was much higher than that by fructoselysine.

Although the TBA method makes it easy to evaluate the extent of lipid peroxidation, its results reflect the total amount of lipid hydroperoxides and secondary degradation products. Thus, we examined POV of the reaction mixtures 


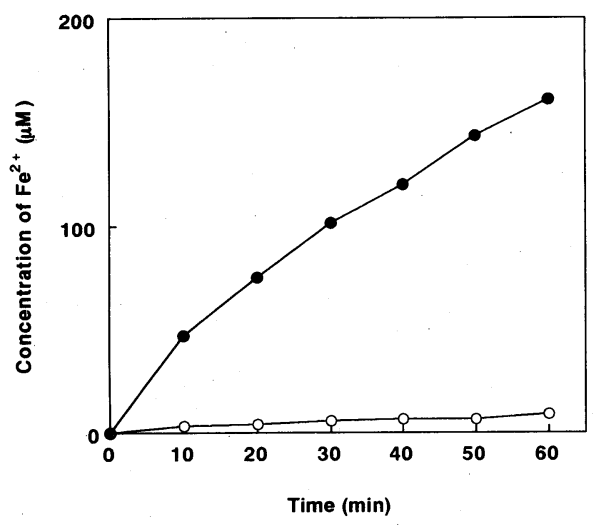

Fig. 4

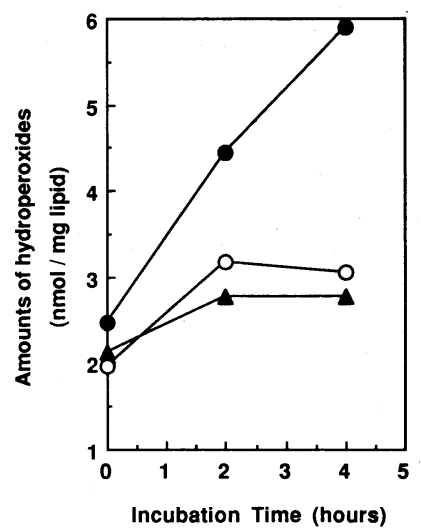

Fig. 5

Fig. 4. Reduction of $\mathrm{Fe}^{3+}$ by glucosone and fructoselysine. Sodium phosphate buffer ( $5 \mathrm{mM}, \mathrm{pH} 7.4$ ) containing $0.2 \mathrm{mM}$ of $\mathrm{FeCl}_{3}, 5 \mathrm{mM}$ of ortho-phenanthroline plus $10 \mathrm{~mm}$ of glucosone $(\bullet)$ or fructoselysine $(O)$ was kept at room temperature. The concentration of $\mathrm{Fe}^{2+}$ was determined as described in MATERIALS AND MEthods.

Fig. 5. Increase of POV in liposomes induced by glucosone. SUV solution $(1 \mathrm{mg}$ liposome $/ \mathrm{ml}$ ) was incubated with $1 \mathrm{~mm}$ glucosone at $40^{\circ} \mathrm{C}$. $\bigcirc$, control; $\bullet$, glucosone; $\boldsymbol{\Delta}$, glucosone with $1 \mu \mathrm{M}$ of EDTA.

to confirm the formation of hydroperoxides of phospholipids. Figure 5 shows that lipid hydroperoxides were accumulated in the liposome during incubation with glucosone under the same conditions as the TBA experiments. Inhibition of EDTA on the increase of POV indicates that metal ions were also responsible for the formation of lipid hydroperoxides.

Since the reaction mixtures were heated in a boiling water bath and absorbance at $535 \mathrm{~nm}$ was measured in the TBA method, there is a possibility that the TBA value might also reflect other factors formed in the heating process than MDA. We tried to confirm MDA formation in the process with the HPLC method, by which MDA can be selectively detected. Figure 6(b) shows that the control liposome treated with urea showed no peak corresponding to 2-hydroxypyrimidine. The peak of glucosone appeared at $4 \mathrm{~min}$ with minor peaks probably due to its degradation products (Fig. 6(d)). A sample prepared from the liposome incubated with glucosone gave a new peak corresponding to 2-hydroxypyrimidine (Fig. 6(a) and (c)). This means that MDA and its precursors were formed during the incubation of liposome with glucosone. In the case of liposome incubated with glucosone and EDTA, the height of the corresponding peak was very low, indicating that metal ions participated in the process of lipid peroxidation (Fig. 6(e)). We compared the value of TBARS measured by TBA method with the value of MDA measured by the HPLC method. Since the value of MDA and TBARS of the same sample in 

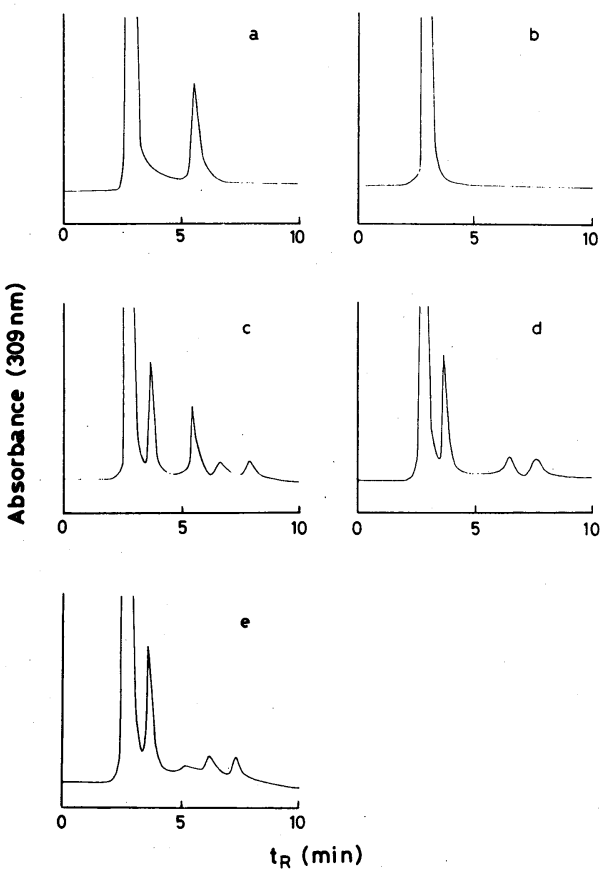

Fig. 6. Chromatograms of the samples treated with urea. Each sample was treated with urea as described in Materials AND Methods. Peaks at $5.5 \mathrm{~min}$ in (a, c, e) indicate formation of 2-hydroxypyrimidine by reaction of urea with MDA present in each sample. (a) authentic MDA, (b) untreated liposome $(1 \mathrm{mg} / \mathrm{ml})$, (c) liposome $(1 \mathrm{mg} / \mathrm{ml})$ incubated with glucosone $(1 \mathrm{mM})$ for $15 \mathrm{~h}$, (d) glucosone (1 $\mathrm{mM})$, (e) liposome $(1 \mathrm{mg} / \mathrm{ml})$ incubated with glucosone $(1 \mathrm{mM})$ in the presence of EDTA $(1 \mu \mathrm{M})$ for $15 \mathrm{~h}$. Injection volume, $50 \mu \mathrm{l}$; column, Develosil ODS-5 reverse-partition column $(4.6 \times 250 \mathrm{~mm})$; eluents, distilled water; flow rate, $1.0 \mathrm{ml} / \mathrm{min}$; temperature, ambient; detection, $\mathrm{UV}$ at $309 \mathrm{~nm}$.

Fig. 6(c) were 6.1 and $5.7 \mathrm{nmol} / \mathrm{ml}$ respectively, the value of TBARS reflected mainly the amount of MDA. These results also show that the HPLC method is effective in studying lipid peroxidation of liposomes.

\section{DISCUSSION}

The finding of the lipid peroxidation induced by glucosone suggests the relation between glycation and lipid peroxidation. It is already known that ascorbic acid induces lipid peroxidation of liposome made of rat liver- and egg yolk-lecithin due to its enediol structure in the presence of $\mathrm{Fe}^{3+}(13-15)$. Since glucosone and fructoselysine can form enediol structure (Fig. 7), it is easy to expect these compounds to induce lipid peroxidation of liposome. Sakurai et al. reported that 


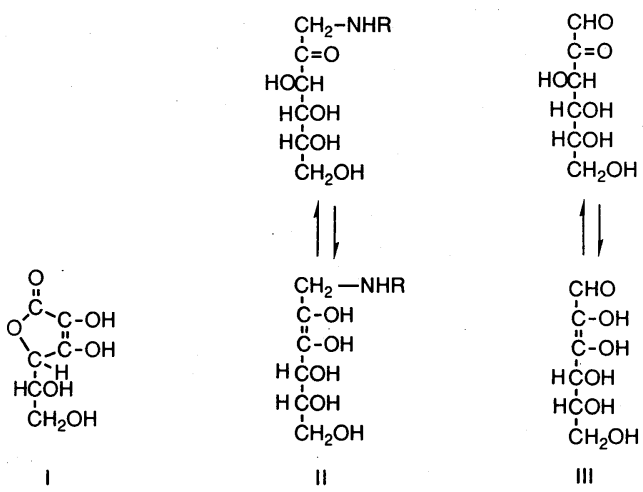

Fig. 7. The structures of the enediol compounds. I. ascorbic acid, II. fructose lysine, III. glucosone.

glycated polylysine, which consists of many Amadori moieties, induced lipid peroxidation of liposome in the presence of $60 \mu \mathrm{M}$ of $\mathrm{Fe}^{3+}(3)$. They assumed active complexes of an Amadori moiety, $\mathrm{Fe}^{3+}$ and oxygen in the glycated polylysine, and ascribed these to lipid peroxidation. They also suggested glycated LDL induced lipid peroxidation of its own lipids with the same mechanism (4). When no metal ions were added to the reaction mixture, lipid peroxidation was not induced by an Amadori compound but by glucosone (Fig. 1). This result indicates reactivity of glucosone is much higher than that of Amadori compounds. Therefore, if Amadori moieties of glycated protein are partly decomposed to lysine and glucosone in the presence of metal ions, the produced glucosone induces lipid peroxidation more efficiently than the Amadori moieties. We think our model system helps in the study of the mechanisms of LDL atherogenicity as a complication of diabetes, because the protein moiety of LDL is glycated much more under diabetic conditions than under normal conditions (4). Hunt et al. supposed that glucose induced lipid peroxidation of LDL in the presence of $\mathrm{Cu}^{2+}(2)$. If the protein moiety is once glycated, degradation of Amadori products easily occurs in the presence of $\mathrm{Cu}^{2+}$ under physiological conditions (5). Therefore, glucosone might be formed in their model system and initiate lipid peroxidation more efficiently than glucose.

The inhibitory effects of EDTA and DTPA on all items examined here shows that trace amounts of metal ions are critical for the lipid peroxidation induced by glucosone (Figs. 2, 5, 6). Although $\mathrm{Cu}^{2+}$ enhanced the lipid peroxidation of the liposomes more efficiently than $\mathrm{Fe}^{3+}$ (Fig. 3), the catalytic effects of $\mathrm{Fe}^{3+}$ seem more important under physiological conditions (2), especially in the lipid peroxidation of LDL. It is well known that lipid hydroperoxides are decomposed to secondary products in the presence of ascorbic acid and metal ions. If so, there is a possibility that glucosone might not be responsible for the initiation of lipid peroxidation but only for the degradation process. We can exclude this possibility by the results of POV experiments and confirm the role of glucosone as an initiator 
of lipid peroxidation, because POV of the liposome also increased during incubation with glucosone (Fig. 5).

Miller and Aust indicated that ascorbic acid reduces $\mathrm{Fe}^{3+}$ to $\mathrm{Fe}^{2+}$ and the resulting $\mathrm{Fe}^{2+}: \mathrm{Fe}^{3+}$ complex promotes lipid peroxidation of liposome (15). Considering that ascorbic acid and glucosone possibly have the same enediol structure (Fig. 7), we propose that the prooxidant effects of glucosone should be ascribed to reduction of metal ions with this structure. Although Amadori compounds can also have the enediol structure (Fig. 7), its reducing properties were much weaker than that of glucosone (Fig. 4), suggesting the reason why fructoselysine did not cause lipid peroxidation in our system. Therefore, it is necessary to investigate the role of glucosone and other enediol products formed from Amadori compounds in the presence of metal ions in order to clarify the mechanism of the lipid peroxidation caused by glycation.

Our findings also suggest that various biological effects of glucosone $(11,12)$ might be related to its prooxidant effects on cell components including lipid bilayers.

\section{REFERENCES}

1) Halliwell, B., and Gutteridge, J. M. C. (1990): Role of free radicals and catalytic metal ions in human disease: An overview. Methods Enzymol., 186, 1-85.

2) Hunt, J. V., Smith, C. C. T., and Wolff, S. P. (1990): Autoxidative glycosylation and possible involvement of peroxides and free radicals in LDL modification by glucosone. Diabetes, 39, 1420-1424.

3) Sakurai, T., Sugioka, K., and Nakano, M. (1990): Oxidative modification of glycated low density lipoprotein in the presence of iron. Biochim. Biophys. Acta, 1043, 27-33.

4) Sakurai, T., Kimura, S., Nakano, M., and Kimura, H. (1991): $\mathrm{O}_{2}{ }^{-}$generation and lipid peroxidation during the oxidation of a glycated polypeptide, glycated polylysine, in the presence of iron-ADP. Biochem. Biophys. Res. Commun., 177, 433-439.

5) Kawakishi, S., Tsunehiro, J., and Uchida, K. (1991): Autoxidative degradation of Amadori compounds in the presence of copper iron. Carbohydr. Res., 211, 167-171.

6) Kato, H. (1963): Chemical studies on amino-carbonyl reaction. Part II. Identification of D-glucose formed by oxidative browning degradation of $\mathrm{N}$-D-glucoside. Agric. Biol. Chem., 27, 461-466.

7) Kawakishi, S., Kito, Y., and Namiki, M. (1975): $\gamma$-Radiolysis of D-glucose in aerated, aqueous solution. Carbohydr. Res., 39, 263-269.

8) Kawakishi, S., Kito, Y., and Namiki, M. (1977): Radiation-induced degradation of D-glucose in anaerobic condition. Agric. Biol. Chem., 41, 951-957.

9) Kito, Y., Kawakishi, S., and Namiki, M. (1979): Radiation-induced degradation of D-fructose in anaerobic condition. Agric. Biol. Chem., 43, 713-718.

10) Kito, Y., Kawakishi, S., and Namiki, M. (1981): Radiation-induced degradation of D-fructose in aerated condition. Agric. Biol. Chem., 45, 1999-2003.

11) Niemand, J. G., Den Drijver, L., Pretorius, C. J., Holzapfel, C. W., and Van der Linde, H. J. (1983): A study of the mutagenicity of irradiated sugar solutions: Implications for the radiation preservation of subtropical fruits. J. Agric. Food Chem., 
31, 1016-1020.

12) Reiffen, K. A., Löffler, M., and Schneider, F. (1981): The effect of glucosone on the proliferation and energy metabolism of in vitro grown Ehrlich ascites tumor cells. $Z$. Naturforsch., 36c, 255-261.

13) Kunimoto, M., Inoue, K., and Nojima, S. (1981): Effect of ferrous ion and ascorbateinduced lipid peroxidation on liposomal membranes. Biochim. Biophys. Acta, 646, 169178.

14) Fukuzawa, K., Chida, H., Tokumura, A., and Tsukatani, H. (1981): Antioxidative effect of $\alpha$-tocopherol incorporation into lecithin liposomes on ascorbic acid-Fe ${ }^{2+}$. induced lipid peroxidation. Arch. Biochem. Biophys., 206, 173-180.

15) Miller, D. M., and Aust, S. D. (1989): Studies of ascorbate-dependent, iron-catalyzed lipid peroxidation. Arch. Biochem. Biophys., 271, 113-119.

16) Bayne, S. (1963): Aldosuloses (osones), in Methods in Carbohydrate Chemistry, ed. by Whistler, R. L., and Wolfrom, M. L., Academic Press Inc., New York, pp. 421-423.

17) Njoroge, F. G., Fernandes, A. A., and Monnier, V. M. (1988): Mechanism of formation of the putative advanced glycosylation end product and protein cross-link 2(2-furoyl)-4(5)-(2-furanyl)-1H-imidazole. J. Biol. Chem., 263, 10646-10652.

18) Buege, J. A., and Aust, S. D. (1978): Microsomal lipid peroxidation. Methods Enzymol., 52, 302-310.

19) Osawa, T., and Shibamoto, T. (1992): Analysis of free malonaldehyde formed in lipid peroxidation systems via a pyrimidine derivative. J. Am. Oil Chem. Soc., 69, 466-468.

20) Tien, M., Morehouse, L. A., Bucher, J. R., and Aust, S. D. (1982): The multiple effects of ethylenediaminetetraacetate in several model lipid peroxidation systems. Arch. Biochem. Biophys., 218, 450-458. 